
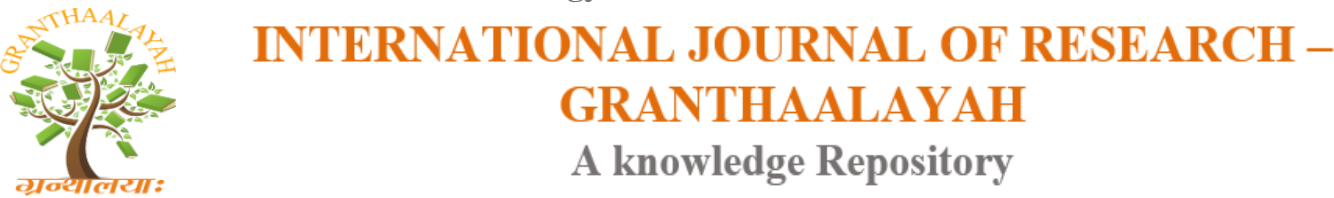

RAST - 17

\title{
ACIDOGENIC OFF GAS DIVERSION: A KEY SOLUTION OF TWO STAGE ANAEROBIC DIGESTION PROCESS FOR FOOD WASTE TO BIOENERGY
}

\author{
Debkumar Chakraborty ${ }^{* 1}$, A.V. Raghu ${ }^{2}$ \\ ${ }^{* 1,2}$ Department of Food Technology, Centre for Emerging Technology, Jain University, 562 \\ 112, India
}

DOI: https://doi.org/10.5281/zenodo.803420

\begin{abstract}
Food waste from households and commercial sources such as canteen, cafeteria and restaurant are usually disposed off in landfills. Limited space and environmental impacts viz generating greenhouse gases and polluting groundwater table are some of the major concerns of food waste disposal in landfill. However, bio processing is a promising alternative for the treatment of food waste due to its high organic content and the potential to recover value added products like biogas and soil conditioner. Two stage anaerobic digestion systems is one of the developed technology in anaerobic digestion system where more energy can be recovered from waste material. But due to its complexity and energy loss researchers need to find probable solution to this and lots of research is going on now a day to improve its energy production rate. Acidogenic off gas diversion is one of the most prominent technology acquire attentions recently. In our discussion we will discuss various prospects of this technology to increase food waste degradation rate.
\end{abstract}

Keywords: Food Waste; Biogas; Anaerobic Digestion; Acidogenic off Gas Diversion.

Cite This Article: Debkumar Chakraborty, and A.V. Raghu. (2017). "ACIDOGENIC OFF GAS DIVERSION: A KEY SOLUTION OF TWO STAGE ANAEROBIC DIGESTION PROCESS FOR FOOD WASTE TO BIOENERGY." International Journal of Research - Granthaalayah, 5(4) RAST, 39-44. https://doi.org/10.5281/zenodo.803420.

\section{Introduction}

\subsection{Food Waste as Energy Source}

Globally, food wastes represent about $30-50 \%$ of the MSW in different countries. Considering the quantity of this waste, now many countries are diverting food waste to 'waste-to-energy' treatment technologies to combat global warming, because degradation of organic wastes in the landfills contribute to methane $\left(\mathrm{CH}_{4}\right)$ emission, representing $\sim 3 \%$ of the total greenhouse gases 
emitted. With constant increase in energy demand and fuel prices, technologies that can generate energy from the organic wastes in a sustainable way will be helpful to save more energy. Among the waste to energy technologies, anaerobic digestion is considered as a viable technology for food waste treatment due to its high moisture content and potential to produce about 200 to 500 L of $\mathrm{CH}_{4} \mathrm{~kg}^{-1} \mathrm{VS}$ (Cho et al., 1995; Hansen et al. 2004). Food waste (FW) has the following typical characteristics a) high moisture content b) good nutrient status and c) high fermentability.

\subsection{Food Waste Composition}

Food waste also has large quantities of organic materials such as proteins, carbohydrates and lipids, varying amounts of suspended solids depending on the source, hence possess high biochemical oxygen demand (BOD). Fruits, vegetables and tubers dominate the food waste. According to the FAO data on global quantitative food losses and waste per year are roughly $30 \%$ cereals, $40-50 \%$ root crops, fruits and vegetables, $20 \%$ oil seeds, meat and dairy plus $35 \%$ for fish. Out of the total food waste generated in India, fruits and vegetables constitute 35-40\%. India, China and other South Asian countries together contribute nearly 50\% of the total food waste generated in the world. Food waste generated from these regions typically contains fruits and vegetables-35-50\%, meat-20\%, fish and sea food-30 \% and dairy products-20\% (FAO, 2009). Fresh vegetables, salad and fruits dominated in the food waste generated at Turkey (70\%), Asia (45-50\%), USA (43\%) and UK (36\%). Dairy and egg waste are majorly found in Netherlands (33\%) and bakery waste in Austria (20\%).

\section{Biogas Production Scenario in India}

Anaerobic digestion is a biological conversion process without an external electron acceptor, such as oxygen, nitrate and sulfate. Anaerobic digestion process is known as the most feasible technology for treating organic waste including food waste. It has also been extensively used in China and India to recover bioenergy from farm yard waste, such as manure. Biogas produced from anaerobic digestion can be used for heating, cooking and lighting applications. In 2014-15, about 20,700 lakh cubic meters of biogas is produced in our country, which is equivalent to only $5 \%$ of the total LPG consumption in the country. A total of 4194 single phase biogas plants were established during this period in 8 different states. When these biogas plants were inspected, unfortunately around $4.5 \%$ of them were non-functional. One of the main reasons could be using old technology that could have led to construction \& maintenance defects. 


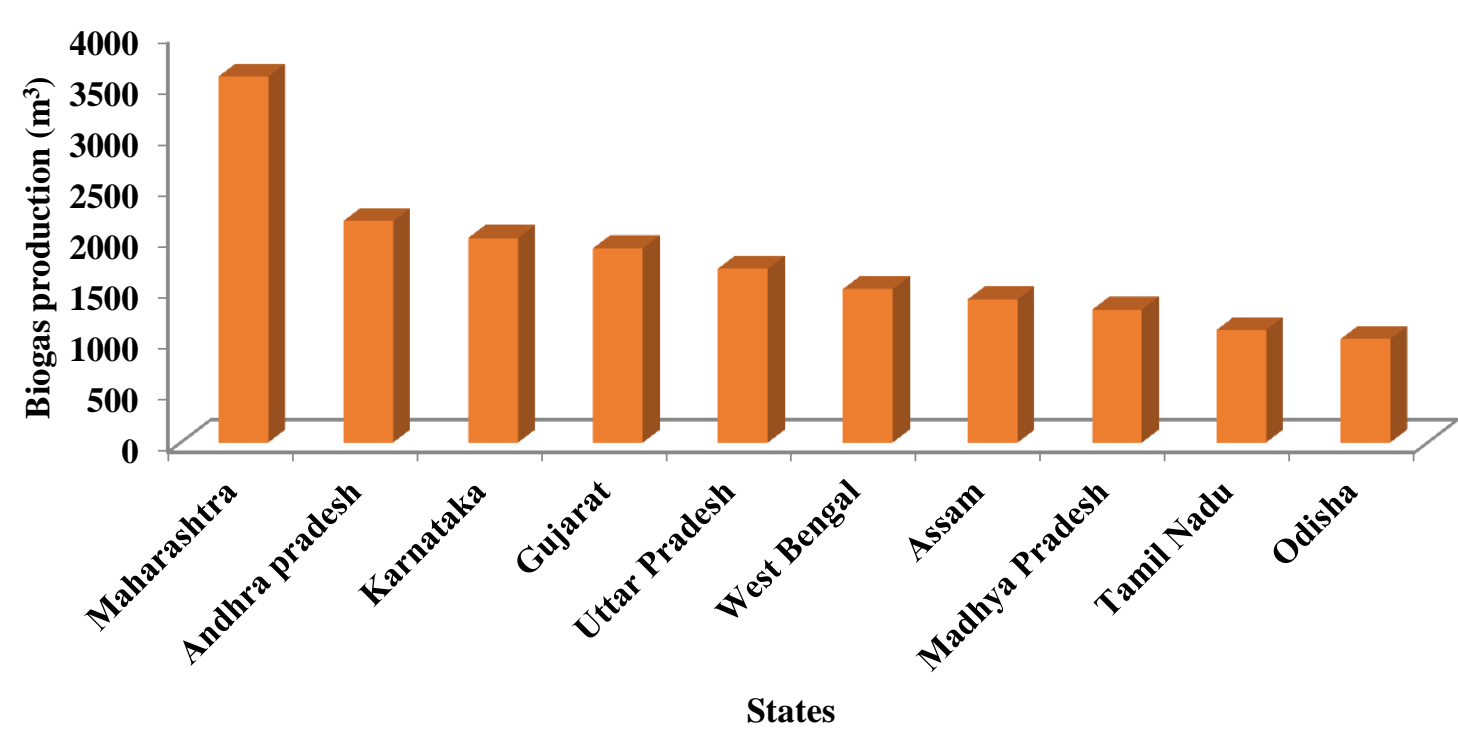

Figure 1: Production of biogas in 2014-15 from various states in India

\section{Two Stage Anaerobic Digestion Process and Biogas Production}

Two phase anaerobic digestion technology would be a probable solution to this problem. In this process, acidogenic and methanogenic phases which were physically separated were demonstrated to have increased stability, operational flexibility and increased processing rate of the substrate. However, considering the operational complexities with additional module, the increase in methane yield was not significantly high when compared to the single-phase reactors implying that the full advantages of this system has not been revealed (Lehtomaki et al., 2008; Selvam et al., 2010; Nizami et al., 2011; Yu et al., 2012). Modernization of two-phase anaerobic digestion process is necessary to address this issue.

\subsection{Problems Associated with Two Stage Anaerobic Digestion Process}

In two phase system, after grinding, food waste is added in open pretreatment chamber to enable hydrolysis, acidogenesis and acetogenesis. Then the partially digested food waste is fed into the methanogenic chamber for methane production. But the methane yield in two phase system at mesophilic condition is quite less than other studies reported in the literature (0.4-0.52) $\mathrm{m}^{3} / \mathrm{kgVS}$ at thermophilic condition (Liu et al., 2009; Kobayashi et al., 2012; Banks et al., 2012). The mass balance analysis on two phase anaerobic digestion system indicates that only $52 \%$ of soluble product contributes towards methane production. This is equivalent to $79 \%$ of $1 \mathrm{~g}$ TOC. According to literature, more than $40 \%$ of energy is generally lost in form $\mathrm{CO}_{2}$ or $\mathrm{H}_{2}$ during two step processes. Acidogenic off gases $\left(\mathrm{CO}_{2}\right.$ and $\left.\mathrm{H}_{2}\right)$ are directly escaping into the atmosphere, leading to "C" emission as well as energy loss. Based on a carbon mass balance analysis from previous studies of food waste in a two-phase anaerobic digestion process, $\sim 28 \%$ of the solids are left undigested, $20 \%$ of the carbon in digested volatile solids (VS) is lost from the acidogenic phase as $\mathrm{CO}_{2}$ (Selvam et al., 2010; Xu et al., 2011, 2012). 


\subsection{Key Solution to Store Energy During Two Stage Anaerobic Digestion Process}

There are two possibilities for $\mathrm{CO}_{2}$ reduction in the methanogenic chamber. One pathway is the homoacetogens-mediated acetate production (eq 1) (Nie et al., 2007; 2008). Alternatively, the $\mathrm{CO}_{2}$ and $\mathrm{H}_{2}$ can directly be reduced to $\mathrm{CH}_{4}$ by hydrogenotrophic methanogens (eq. 2), which play significant role in the methanogenic reactors.

$$
\begin{aligned}
& \left.4 \mathrm{H}_{2}+2 \mathrm{CO}_{2} \rightarrow \mathrm{CH}_{3} \mathrm{COO}-+\mathrm{H}++2 \mathrm{H}_{2} \mathrm{O} \Delta \mathrm{G} 0=-95 \mathrm{~kJ} / \mathrm{mole} \ldots \ldots \ldots \text { (Eq } 1\right) \\
& 4 \mathrm{H}_{2}+\mathrm{CO}_{2} \rightarrow \mathrm{CH}_{4}+2 \mathrm{H}_{2} \mathrm{O} \quad \Delta \mathrm{G}^{0}=-131 \mathrm{~kJ} / \mathrm{mole} \ldots \ldots . . \mathrm{Eq}(2)
\end{aligned}
$$

As Schievano et al. (2012) reported, the use of an $\mathrm{H}_{2}$ producing acidogenic stage may alter the acidogenic leachate quality that influences the overall efficiency of the AD process. In the diphasic anaerobic digestion (LBR-UASB) study done by Xu et al., (2011, 2012), they diverted the off-gas from the LBR to the methanogenic UASB reactor. Results revealed that this process design (1) increased the digestion of solids in the LBR by $15.4 \%$, (2) increased the overall methane production by $26 \%$ as well as increased the methane yield to $0.39 \mathrm{~L} \mathrm{CH} 4 / \mathrm{g}$ COD removed against $0.33 \mathrm{~L} \mathrm{CH}_{4} / \mathrm{g}$ COD removed in the control. In another study reported by (Yan et al., 2016) for maximum energy recovery $\mathrm{H}_{2}$ and $\mathrm{CO}_{2}$ produced in the acidogenic reactor was fed to the methanogenic reactor which increased the energy production by $30 \%$. They observed head space $\mathrm{H}_{2}$ partial pressure affected the soluble product speciation and $\mathrm{pH}$ in LBR (hydrolysis and acidogenic chamber). Continuous mode of LBR operation enables to obtain a regular feed stock and increases the methane yield (Xu et al., 2012). $p \mathrm{H}$ and VFA distribution greatly influences the methane production and energy recovery in anaerobic digestion system. Rapid acid production during the initial stage of the acidogenesis increases the production of ethanol (Karthikeyan et al., 2011; $\mathrm{Xu}$ and Wong, 2011). A proper volatile fatty acid distribution (acetate to butyrate ratio and acetate to propionate ratio) is necessary for higher methane production (Karthikeyan et al., 2016). A high concentration of VFAs has been reported to inhibit methane production from VFAs by mixed anaerobic microorganisms too (Siegert and Banks, 2005; Wang et al., 2005). The key factors affecting the metabolic pathways and leachate quality are low $\mathrm{pH}$, acid accumulation and headspace $\mathrm{H}_{2}$ concentration in acidogenic reactors. In the two-phase setup, the quality of acidogenic leachate would significantly influence the methane production in the methanogenic chamber. In a steady state, the microbes could adapt to the condition and in the long run, the $\mathrm{H} 2$ production in the acidogenic chamber could be increased.

\section{Conclusion}

Targeting probable cause of less methane yield in the biogas plant can be explained with following reasons. First, residual organic matter after hydrolysis/acidogenesis is quite high and partially digested matter sent to methanogenic tank, implying that the hydrolysis process needs to be improved. Secondly, energy loss from hydrolysis/acidogenic chamber should be minimized. The generated Lactic acid shows very low $p \mathrm{H}$ (around 3.3 to 3.8) should be inhibited and using buffering agents. Continuous details study is required for identifying the route of increased methane production using acidogenic gas transfer and investigating the factors affecting the leachate quality and dynamics of fatty acids in hydrolysis/acidogenicand methanogenic reactor. Finally a kinetic model is required for operating the hydrolysis/acidogenesis in a continuous mode for higher energy recovery from food waste using two stage approaches. 


\section{Acknowledgements}

We thank the Ministry of Food Processing and Industries, (MOFPI), Government of India for the award of research project.

\section{References}

[1] Cho JK, Park SC, Chang HN. 1995. Biochemical methane potential and solid state anaerobic digestion of Korean food wastes. Biores. Technol. 52: 245-253.

[2] Hansen TL, Schmidt JE, Angelidaki I, Marca E, Jansen JC, Mosbæk H, Christensen TH.2004. Method for determination of methane potentials of solid organic waste. Waste Manage. 24: 393-400.

[3] Lehtomaki A, Huttunen S, Lehtinen T, Rintala JA. 2008. Anaerobic digestion of grass silage in a batch leach bed processes for methane production. Biores. Technol. 99: 32673278.

[4] Nizami AS, Singh A, Murphy JD. 2011. Design, commissioning, and start-up of a sequentially fed leach bed reactor complete with an upflow anaerobic sludge blanket digesting grass silage. Energy \& Fuels 25:823-834.

[5] Selvam A, Xu SY, Gu XY, Wong JWC. 2010. Food waste decomposition in leachbed reactor: Role of neutralizing solutions on the leachate quality. Biores. Technol. 101: 1707-1714.

[6] Karthikeyan OP, Selvam A, Xu SY, Wong JWC. 2011. Food waste hydrolysis in SLSCSTR under low organic loading rate: Effect of $\mathrm{pH}$ and metabolite distribution. Proc. Intl. Conf. Solid Waste 2011 - Moving Towards Sustainable Resource Management, J.W.C. Wong, K.Fricke, R.Y. Surampalli and A. Selvam (Editors), Hong Kong Baptist University, HongKong SAR, P.R. China. pp. 440-442.

[7] Xu SY, Wong JWC. 2011. Solubilization of organic acids from food waste under microaerobic condition - a batch study using anaerobic solid-liquid system. Intl. IWA-Symp. AnaerobicDigestion of Solid Waste and Energy Crops, Aug 28-Sept 1, 2011, Vienna, Austria.

[8] Xu SY, Lam HP, Karthikeyan OP, Wong JWC. 2011. Optimization of food waste hydrolysis in a leach bed coupled with methanogenic reactor: effect of $\mathrm{pH}$ and bulking agent, Biores. Technol. 102:3702-3708.

[9] Xu SY, Selvam A, Wong JWC. 2012. Comparison of batch and semi-continuous acidogenic process of food waste anaerobic digestion. In: Proc. ORBIT2012, June 2012, France.

[10] Yu L, Zhao Q, Ma J, Frear C, Chen S. 2012. Experimental and modeling study of a twostage pilot scale high solid anaerobic digester system. Biores. Technol. 124: 8-17.

[11] Schievano A, Tenca A, Scaglia B, Merlino G, Rizzi A, Daffonchio D, Oberti R, Adani F. 2012. Two-stage vs single-stage thermophilic anaerobic digestion: comparison of energy production and biodegradation efficiencies. Environ. Sci. Technol. 46: 85028510.

[12] Xu SY, Karthikeyan OP, Selvam A, Wong JWC. 2012. Effect of inoculums to substrate ratio on the hydrolysis and acidification of food waste in leach bed reactor. Biores. Technol.126: 425-430. 
[13] Drake HL, Gossner AS, Daniel SL.2008. Old acetogens, new light. Ann. N.Y. Acad. Sci. 1125: $100-128$

[14] Kim JK, Oh BR, Chun YN, Kim SW. 2006. Effects of temperature and hydraulic retention time on anaerobic digestion of food waste. J. biosci. Bioengineer. 102(4): 328332.

[15] Misoph M, Drake HL. 1996. Effect of CO2 on the fermentation capacities of the acetogen Peptostreptococcusproductus U-1. J. Bac. 178: 3140-3145.

[16] Nie Y, Liu H, Du G, Chen J. 2008. Acetate yield increased by gas circulation and fedbatch fermentation in a novel syntrophic acetogenesis and homoacetogenesis coupling system. Biores. Technol. 99: 2989-2995.

[17] Nie YQ, Liu H, Du GC, Chen J. 2007. Enhancement of acetate production by a novel coupled syntrophic acetogenesis with homoacetogenesis process. Process Biochem. 42(4): 599-605.

[18] Yan BH, Selvam A, Wong JWC. 2016. Innovative method for increased methane recovery from two-phase anaerobic digestion of food waste through reutilization of acidogenic off-gas in methanogenic reactor. Biores. Technol. 217: 3-9

[19] Wang J, Zhang H, Stabnikova O, Ang S, Tay J. 2005. A hybrid anaerobic solid liquid system for food waste digestion. Water Science Technol. 52(1-2): 223.

*Corresponding author.

E-mail address: debkumarchakraborty@yahoo.co.in 